\title{
Courageous conversations in supervision
}

Allyson Davys, University of Auckland, New Zealand

\begin{abstract}
INTRODUCTION: Courageous conversations, commonly identified as conversations which are associated with some form of emotion, are features of many social workers' daily routine. In supervision, such conversations are typically required to address issues of supervisee professional competence, ethical issues or the supervision relationship and/or process. These conversations, which are challenging, are at times avoided and, at other times, may be poorly handled.
\end{abstract}

APPROACH: Following identification of the obstacles which may impede addressing challenging issues in professional practice, this article focuses the supervisor's role in courageous conversations. The importance of building a supervision environment which can support robust conversations is highlighted. Here the contracting process, where the expectations of supervision are negotiated and the power inherent in the supervision relationship can be identified, is considered foundational. The skills and attributes needed by the supervisor to manage these difficult encounters are explored and three kinds of interventions are identified as helpful: relational, reflective, and confrontational. A framework for a courageous conversation is provided which highlights the need for clarity about the motivation, purpose and desired goals. Finally, a structure for the proposed conversations is presented.

IMPLICATIONS: With an understanding of the dynamics and of the skills required, supervisors can better prepare themselves for courageous conversations. When supervision relationships are based on negotiation and shared understanding about power, difference and expectations, hard issues can be raised and honestly confronted and at the same time the integrity of all involved can be maintained.

KEYWORDS: Supervision; courageous conversations; professional expectations; preparation; interventions

“The art of conversation is the ability to create a dialogue that others will willingly join." (Whyte, 2004, p. 20)

In this definition, where a conversation can be considered as an exchange of ideas or views between two (or more) people, Whyte (2004) captures both the essence and the challenge of courageous conversations. To engage in such an exchange, both parties need to be open to hearing and considering the positions and views of the other. When the topic at hand is challenging, when it concerns conflicting views and values and when there is an element of power in the relationship, it can be hard for either party to remain listening and open to the dialogue. Past experiences of poor and unsafe communication, lack of confidence that change is possible and lack of skills in this sort of exchange are all reasons why challenging and courageous conversations are avoided or go wrong. In supervision, attention to the establishment of a relationship where the expectations, needs and the parameters of authority are clear and negotiated can lay the foundation 
for constructive courageous conversations. In addition, it can be helpful for the supervisor to review his or her approach to these conversations. What skills does he or she bring, how will they be utilised and what is the overall strategy to address these challenging situations?

\section{Obstacles to courageous conversations in professional practice}

Courageous conversations occur at all stages of professional and career development and attitudes and confidence for these conversations may have been shaped by early experiences. When anti-discrimination and anti-oppression are the foundational premises of practice (Brown \& Bourne, 1996; Falender \& Shafranske, 2014; Hair, 2014; Hawkins \& Shohet, 2012; Tsui, O'Donoghue, $\& \mathrm{Ng}, 2014)$, experiences of courageous exchanges may begin in the educational setting. In these early conversations the values and practice ethics of the profession may well challenge and come into conflict with the personal values and beliefs of students. At the same time, the power and authority of the academic staff or supervisor, derived from their role and expertise, can be inhibiting factors which potentially silence students. Reporting on a review of conversations about "isms, power, privilege, and oppression", Werman, Adlparvar, Horowitz, and Hasegawa (2019, p. 251) record the perceptions of both social work students and faculty members from a graduate school of social work in New York. Despite the faculty's expressed high level of confidence in their ability to facilitate these sensitive conversations, the students in this study reported "feeling unsafe and unsupported in their classrooms and fearful about speaking up to faculty" (p. 261). The memories of such experiences may well shape the attitudes and subsequent behaviour of these students as they move into professional practice.

Following qualification, courageous conversations in the workplace often involve confronting colleagues and peers about their behaviour and the literature highlights the obstacles which can get in the way of this happening. Grenny (2009), studying relationships between healthcare professionals in the United States, identified seven particularly difficult conversation topics, aptly named the "seven zones of silence" (p. 424). These topics included: broken rules, mistakes, lack of support, incompetence, poor teamwork, disrespect and micromanagement (Grenny, 2009, pp. 242-243). Despite $75 \%$ of respondents in the study having experienced rudeness, insult and condescension, the respondents reported that it was difficult, or impossible, to confront the person responsible for the behaviour. The study found that there was less than a $7 \%$ chance of this occurring. Three key obstacles to addressing this behaviour were named as "lack of ability, belief that it is not their job and low confidence that it will do any good" (Grenny, 2009, p. 424). Failure to address any of these issues, as the study illustrates, only extended the dysfunction.

Other studies have identified obstacles to initiating courageous conversations such as fear of offending, or causing distress to, another person (Brown et al., 2011; Grant, Schofield, \& Crawford, 2012), fear of being blamed or being unable to handle a possible emotional response (Lamiani et al., 2011, p. e57), fear of the negative effects on the relationship, and fear of compounding the problem (Grant et al., 2012). In these sorts of situations Meyer et al. (2009, p. 352) note that a typical response is to "delay, avoid, or delegate".

All of these obstacles can shape the way in which challenging situations are addressed in supervision. Quarto (2003) found that inexperienced supervisors, concerned to prove themselves as effective, were more likely to assume authoritative control rather than seek to understand the opinion of the supervisee. When faced with differences of opinion about case conceptualisation and the influence of the supervisees' own issues on their work, Bang and Goodyear (2014) report 
that "supervisors dismissed supervisees' thoughts and feelings" and, in response, supervisees "experienced negative emotions and became less involved in supervision" (Bang \& Goodyear, 2014, p. 372). Other unhelpful interventions "characterised by confrontational criticism, direct attribution of blame, unclear agendas, and instructive rather than interactive learning processes" have led to what has been described as "problematic supervision" (Grant et al., 2012, p. 528).

\section{Courageous conversations in supervision}

Difficult issues do arise in supervision, and need to be addressed by the supervisor. These issues typically concern one of three, often interconnected, areas: practice competence, professional boundary and ethical violations, and relationship issues (Beddoe \& Davys, 2016, p. 197). It is useful to note the alignment of these three areas with Grenny's (2009) "seven zones of silence" discussed earlier. Conflict, or fear of conflict in these conversations, is frequently an element which may evoke the "delay, avoid or delegate" response (Meyer et al., 2009).

At times the supervision conversation may be a consequence of existing conflict while, at other times, the conversation itself may challenge ideas, values or behaviour and so may provoke conflict. If the conversation is concerned with issues of ethics, competence or values, a reluctance from the supervisor to proceed with the conversation may also be a reflection of the possible impact on existing relationships as well as the consequences of such conversations on future employment. As Bang and Goodyear (2014) observe, however, in supervision it is not the conflict which is so important but rather it is the way in which the people concerned handle and respond to that conflict. When conflict is managed well and resolved, relationships deepen and strengthen; conversely when conflict is not handled well the relationships may falter and sour. Employing Nelson and Friedlander's (2001) term "non-productive conflict" for the situations where conflict is poorly handled and not resolved, Bang and Goodyear (2014) describe the distrust, self-doubt and the powerlessness which supervisees experience in these situations.

\section{Building from the start-the supervision contract}

It is well established in the supervision literature that the supervision relationship is the basis for good and effective supervision (Beinart \& Clohessy, 2017; Bernard, 2006). It is therefore helpful to consider how the foundation for possible courageous conversations between a supervisor and a supervisee can be prepared at the beginning of the supervision relationship.

This relationship begins, for many supervision partnerships, through the negotiation of the supervision contract (Davys \& Beddoe, 2010). A supervision contract or agreement, a requirement of many professional bodies, is included by Ellis et al. (2014) in their list of criteria for "minimally adequate clinical supervision" (p. 439). It is worth noting here the difference between a standardised formulaic supervision contract which is presented to the supervisee for signature (which can thus be checked off as a compliance measure), and a supervision contract which is negotiated and developed through discussion of the needs and expectations of both parties. In Aotearoa New Zealand the supervision policies of both the professional social work body, the Aotearoa New Zealand Association of Social Workers (ANZASW, 2015) and the regulating body, the Social Workers Registration Board (SWRB, 2015), require supervision to be based on a negotiated, written agreement. The ANZASW policy stipulates that the contract negotiation also provides for conflict resolution. While it may appear contradictory to introduce the idea of conflict and disagreement at the beginning of a relationship, early discussion and agreement about how difference and conflict will be handled in the relationship can provide clarity and transparency which, 
in turn, develops trust. "Trust" according to Rousseau, Sitkin, Burt, and Camerer (1998, p. 395) "is a psychological state comprising the intention to accept vulnerability based upon positive expectations of the intentions or behaviour of another."

Three components of the contracting process provide the foundation for effective courageous supervision conversations. The first is the identification of the mandated professional behaviour expected of both the supervisor and the supervisee. The second is the negotiation of the ways in which diversity, difference and conflict will be acknowledged and addressed in any particular supervision relationship. The third is the agreement on how feedback will be given and received in the supervision relationship by both the supervisor and the supervisee.

Professional behaviour is mandated through both professional and organisational policy. Referencing this professional and organisational accountability in the supervision contract provides a definitive, non-negotiable baseline for conduct and behaviour along with reference to the mechanisms for addressing any infringements of that conduct and behaviour. Currently in Aotearoa New Zealand there is no unified regulatory or professional accountability for social workers. At the time of writing, social workers have the choice of whether to be registered with the SWRB under the Social Workers Registration Act 2003, and they have a choice as to whether to be a member of the professional body, ANZASW. Social workers at present may therefore be accountable to the professional standards and Code of Conduct of the SWRB or the Code of Ethics of the ANZASW (or both) or they may have no formal line of professional accountability. This choice will soon be removed. Following the passing into law of the Social Workers Registration Legislation Act 2019, all social workers will be required to be registered with the SWRB and will thus be accountable to the requirements of that authority.
The SWRB Code of Conduct (2018) details and provides guidance on 11 principles which provide "minimum professional standards of integrity and conduct" and is "specific about what actions are appropriate and inappropriate" (p. 2). In the accompanying guide, social workers are advised that "if confronted by professional misconduct, you have an ethical duty to report it to your manager, employer, to the SWRB, or to the appropriate authority" (SWRB, 2018, p. 23). In summary, "delay, avoidance or delegation" are not considered by the SWRB to be valid actions.

In addition to professional social work standards, social workers who are employed by an organisation or institution will be subject to the policies and protocols of their organisation or institution and any legislation which relates to their work in that context. These professional and organisational documents serve courageous conversations in a number of ways. From the very beginning of the supervision relationship, the participants are reminded that they are accountable to overarching codes of conduct which have named processes for addressing infringements of those codes, and, they are reminded that, in some situations, they have an ethical duty to take action. With this clarity, rather than arguing over personal values, the supervisor and supervisee have the freedom to discuss issues and situations from within a professional framework. "Communicating clear expectations for competence need not involve conflict. The supervisor should continually strive to maintain an attitude and spirit of collaboration and support for and with the supervisee" (Cohen-Filipic, \& Flores, 2014, p. 306).

The second component addressed in the supervision contract, which builds the supervision relationship and strengthens the platform for courageous conversations, is the manner in which diversity and power between the supervision partners is addressed. This process, named by Hernández and Rankin (2008) as relational 
safety, can be described as "the coconstruction of a dialogical context in which [supervisees] and supervisors are able to raise questions, challenge points of view, ponder issues, confront opinions, articulate ideas, and express concerns" (p. 255).

The supervision relationship, as noted earlier, is a power relationship (Hernández \& McDowell, 2010). For supervisors, positional power accompanies the role of supervisor where both professional and organisational accountability are explicit (Hair, 2014). When, as is common in social work, supervisors hold dual roles of supervisor and line manager (Beddoe, 2010), additional power, sometimes referred to as reward or coercive power (Hawkins \& Shohet, 2012) is present, and this can further shift the power imbalance. Finally, the knowledge and experience of the supervisor brings expert power. In a study of power relationships in social work supervision Hair (2014) found that social work supervisees want supervisors "who are transparent about their positional power" (p. 113) and who, through a shared process of knowledge exchange and critical reflection, engage with the supervisee in the deconstruction of expert power. When both supervisee and supervisor are clear about the rules of the supervision relationship, when power, privilege, diversity and oppression are acknowledged and where there is agreement about how these can, and will, be raised, discussed, challenged and reflected on, the supervisee can be more confident about how he or she will engage.

The third component of the supervision contract which can influence courageous conversations is the manner in which feedback will be given and received by both supervisee and supervisor. "Feedback is an essential element in supervision" (Hewson \& Carroll, 2016, p. 127) and effective feedback is that which occurs as a collaborative exchange between the recipient and giver of feedback (Hewson \& Carroll, 2016). In preparation for feedback in supervision, the questions to consider can thus include: What does feedback mean in this context? How is it defined? Does feedback raise issues for consideration and reflection or is feedback intended as a requirement for change? How does the supervisee like to receive feedback? How can the feedback exchange (giving and receiving) be negotiated to ensure that it is heard and considered? How will the supervisor get feedback? How will they evaluate their supervision relationship and process? What could get in the way?

These three components of the contracting process: identifying the professional baseline of conduct, exploring the mechanisms for conversations of difference and power, and negotiating a collaborative process for giving and receiving feedback, firmly position supervision as a process of openness, enquiry and learning as opposed to one of evaluation and judgement. A climate has been established where trust can grow and where there are guidelines to support difficult conversations.

\section{Supervisor attributes for effective courageous conversations in supervision}

As anticipated in the discussion of the negotiation of the supervision contract, courageous conversations are likely to be more successful when they are conducted in an environment where there is trust and where there are broad agreed parameters to shape the conversation. From a survey of 128 individuals who had graduated from, or were currently enrolled in, doctoral programmes in psychology or other related programmes and who reported on the best and the worst supervisors they had experienced, Ladany, Mori, and Mehr (2013) found that effective supervision "encouraged autonomy, strengthened the supervisory relationship, and facilitated open discussion" (p. 28).

In effective supervision, the attributes of the participants, particularly the supervisor, are important. "Self-awareness, a willingness to acknowledge personal responsibility, 
an openness to other perspectives, good communication skills and a professional approach to practice" have been noted (Beddoe \& Davys, 2016, p. 195). Nelson, Barnes, Evans, and Triggiano (2008) found that supervisors who were regarded as competent at managing conflict were seen to be: "open to conflict and interpersonal processing, willing to manage shortcomings, developmentally orientated, and willing to learn from mistakes. They believed in creating strong supervisory alliances, discussing evaluation early on, modelling openness to conflict and providing timely feedback" (p. 172). Respect and humility (Brown et al., 2011), the ability "to embrace uncertainty and complexity" (Browning, Meyer, Truog, \& Solomon 2007, p. 909), and a willingness to seek consultation and supervision (Grant et al., 2012; Nelson et al., 2008, Veach et al., 2012) also feature in the literature as important attributes.

\section{The courageous conversation: preparation}

As in many matters of competent professional practice, self-awareness can be regarded as the first step to addressing tricky and difficult issues. Until a situation is noticed and valued, it cannot be addressed. The supervisor therefore needs to be alert to the cues and the triggers which indicate that there is possibly an issue. Henderson (2009, p. 19) notes that a feeling of having "to walk on eggshells" signals to her that there is an issue which she needs "to take courage to name" (p. 19). Bang and Goodyear (2014), when considering conflict in the supervision relationship, similarly require the supervisor to be aware of the conflict and further, believe that the power accorded to the supervisor in the supervision process "gives them greater responsibility for resolving it" (p. 354).

Preparation is important and, having identified that there is an issue, three questions can help to clarify the dimensions of this issue and shape how it can be addressed: What is the issue? What is the desired outcome for the individuals concerned? What is the desired outcome for the relationship? The following table expands these questions to help to clarify a way forward.

Table 1 Preparing for a Challenging Conversation

- What is the issue which needs addressing?

- Is there more than one issue?

- Why is the issue important?

- Why is it challenging for me to address this issue with this person?

- What are my feelings about this issue?

- What are my feelings about the person concerned?

- What are my feelings about me and my role in this situation?

- How might those feelings affect the conversation?

- Can I articulate the issue?

- Do I have examples of behaviour or events which illustrate the issue?

- What is the message I wish to communicate?

- What is the outcome I am seeking from this conversation?

- What is my motivation for having this conversation?

Source: Beddoe \& Davys (2016, p. 197). With kind permission of Jessica Kingsley Publishers

\section{The courageous conversation: the skills}

Regardless of the issue, a conversation is a dialogue between at least two people where there is an opportunity for each to present their position and to be heard. This definition possibly best encapsulates the difference between courageous conversations, other assertive and challenging exchanges and disciplinary telling offs. As noted, when negotiating the supervision contract, and when considering the attributes needed by supervisors for successful courageous conversations, the emphasis is on creating a safe place for understanding and for dialogue. "To have an authentic conversation" Koenig (2013, p. 28) advises, it is necessary to be open to the views of the other person and not to impose your opinions and argument. The manner in which a supervisee is invited to this conversation may be the difference between 
them perceiving it as a lecture or as an opportunity to be heard.

Grant et al. (2012), in an exploration of how experienced supervisors managed difficulties in supervision, identified four groups of interventions which were employed by the supervisors: relational, reflective, confrontational and avoidant. The first three of these comprised a hierarchy of interventions which moved from relational exchange, to reflective exploration and challenge, and finally, to confrontational interventions.

Relational interventions, Grant et al. describe as being focused on the "supervisory relationship, the supervisee relationship with the client and the supervisee relationship with self" (Grant et al., 2012, p. 532). The strategies used in these interventions included focused attention on the supervisee's issue(s), the provision of support (practical and emotional), and affirmation and constructive feedback. The supervisors were willing to acknowledge their actions and mistakes, named issues early, negotiated ways to address them and provided a model for the desired behaviour (Grant et al., 2012).

When conversations are considered to require courage, regardless of the supervisor's skill, they can be accompanied by anxiety. Anxiety can have a number of effects, one of which is that the speaker becomes rushed and listening is overtaken by the desire to talk. Frequently too, the person invited to engage in a conversation has had less time to consider the issue. Koenig (2013) recommends a pause: "Be spacious. You may have been thinking about this conversation for a long time. However, the other person may be surprised and need space to take in what you are inviting them to look at" (p. 29).

Rock (2006) provides a useful model for these occasions which he names "speaking with intent". Speaking with intent entails "being succinct, being specific and being generous" (p. 85). Being succinct requires the speaker to be clear about what he or she wants to say and to deliver the message simply and in a manner which the listener can assimilate. Being specific includes appropriate detail for the listener to understand the message. Finally, being generous ensures that the other person understands what the speaker is saying, matching language and providing examples.

The use of "I statements" by the supervisor in these conversations clarifies ownership of thoughts and experience and leaves space for the supervisee. The supervisee can be invited to share his or her story and perspective and the supervisor can listen. Listening generously can be, at these times, one of the greatest challenges for supervisors (Beddoe \& Davys, 2016, p. 199).

A framework for these conversations is presented in Table 2.

Table 2: Framework for the Conversation

Before the conversation:

- Advise the supervisee of the need for the conversation

- Check when is a good time for that person

During the conversation:

- Be clear about what the issue is for you

- Articulate it as clearly and simply as you can

- Be specific, give examples and use 'l' statements

- If appropriate share how you are feeling about the issue and/or the conversation

- Ask the supervisee how he or she is feeling

- Identify the outcome you are wanting from the conversation

- Take responsibility for own behaviour and admit to any mistakes

- Ask for the supervisee's side of the story

- Ask open questions

- Wherever possible validate the supervisee

- Listen generously

- Clarify and summarise

- Listen some more ....

- Identify a way forward and agree to the process

Source: Beddoe \& Davys (2016, p. 200). With kind permission of Jessica Kingsley Publishers 
The second group of interventions, reflective interventions (Grant et al., 2012, p. 533), moves the focus of the conversation towards facilitating the supervisee to consider his or her situation in more depth. Reflection, as described by Hewson and Carroll (2016), involves "paus[ing] to notice and then consider the meaning of what you have noticed" (p. 10). Through reflective questions the supervisor takes an active, and at times, a possibly more challenging role. The supervisee's ideas, motivation, feelings and knowledge may be noticed and explored and the supervisor may offer information and conceptual frameworks to assist exploration and understanding. At the same time, Grant et al. (2012) note the need for the supervisor to be aware of, and to manage, his or her own response to the supervisee's possible defensiveness or resistance.

In this hierarchy of interventions, confrontational interventions, the third type identified by Grant et al. (2012), were used by the supervisors "when attempts to address difficulties through reflective or relational interventions were unsuccessful" (p. 534). Ranging from tentative to direct confrontation, these interventions were more often used when inappropriate behaviour and/or attitudes were the focus of the conversation. At this level of intervention, additional actions, for example referral for therapy or remedial education were sometimes included. When the behaviour or situation was of particular concern, and especially when it breached professional or organisational codes, notification of the situation to management or to appropriate professional bodies occurred. These conversations are most likely to reference those professional standards and codes identified during the drawing up of the supervision contract and to acknowledge that, in some situations, specific action steps are prescribed. For many supervisors taking this ultimate step of notifying a higher or a disciplinary authority is not easy or pleasant and this is the time when their own supervision, consultation and support are most important.
The fourth type of interventions identified by Grant et al. (2012) were avoidant interventions: "struggle on and await external intervention", "withhold" (affirmation), "withdraw, ignore or deny" (pp. 535-536). Consistent with the discussion earlier in this article, the participants in the study noted that avoidant interventions stemmed from lack of confidence, lack of skill and from fear of upsetting the supervision relationship and were typical of their early supervision practice. As the participants developed skill and competence as supervisors, these interventions were no longer used.

\section{Conclusion}

For many social workers advocating for the rights of a client is easier than advocating for one's self or standing up to colleagues and peers or addressing difficult situations with a supervisee. Courageous conversations, when well managed in supervision, however, can model competence in dealing with the more person-centred conflict which occurs between professionals. Wellmanaged courageous conversations can deepen relationships, develop practice and professional awareness, provide learning for all involved and, importantly, can build confidence.

\section{References}

Aotearoa New Zealand Association of Social Workers. (2015). Supervision policy. Christchurch, NZ: ANZASW. Retrieved from http://anzasw.nz/anzasw-publications-2/

Bang, K., \& Goodyear, R. K. (2014). South Korean supervisees' experience of and response to negative supervision events. Counselling Psychology Quarterly, 27(4), 353-378.

Beddoe, L. (2010). Surveillance or reflection: Professional supervision in "the risk society". British Journal of Social Work, 40(4), 1279-1296. doi:doi:10.1093/bjsw/bcq018

Beddoe, L., \& Davys, A. (2016). Challenges in professional supervision: Current themes and models for practice. London, UK: Jessica Kingsley.

Beinart, H., \& Clohessy, S. (2017). Effective supervisory relationships: Best evidence and practice. Hoboken, NJ: John Wiley \& Sons.

Bernard, J. M. (2006). Tracing the development of clinical supervision. The Clinical Supervisor, 24(1), 3-21.

Brown, A., \& Bourne, I. (1996). The social work supervisor. Buckingham, UK: Open University Press. 
Brown, J., Lewis, L., Ellis, K., Stewart, M., Freeman, T. R., \& Kasperski, M. J. (2011). Conflict on interprofessional primary health care teams - can it be resolved? Journal of Interprofessional Care, 25(1), 4-10. doi:10.3109/1356 1820.2010.497750

Browning, D. M., Meyer, E. C., Truog, R. D., \& Solomon, M. Z (2007). Difficult conversations in health care: Cultivating relational learning to address the hidden Curriculum. Academic Medicine, 82(9), 905-913.

Cohen-Filipic, J., \& Flores, L. Y. (2014). Best practices in providing effective supervision to students with values conflicts. Psychology of Sexual Orientation and Gender Diversity, 1(4), 302-309.

Davys, A., \& Beddoe, L. (2010). Best practice in professional supervision: A guide for the helping professions. London, UK: Jessica Kingsley.

Ellis, M. V., Berger, L., Hanus, A. E., Ayala, E. E., Swords, B. A., \& Siembor, M. (2014). Inadequate and harmful clinical supervision: Testing a revised framework and assessing occurrence. The Counseling Psychologist, 42(4), 434-472. doi:10.1177/0011000013508656

Falender, C. A., \& Shafranske, E. P. (2014). Clinical supervision: The state of the art. Journal of Clinical Psychology, 70(11), 1030-1041.

Grant, J., Schofield, M. J., \& Crawford, S. (2012). Managing difficulties in supervision: Supervisors' perspectives.' Journal of Counseling Psychology, 59(4), 528-541. doi: $10.1037 / \mathrm{a} 0030000$

Grenny, J. B. S. (2009). Crucial conversations: The most potent force for eliminating disruptive behavior. Health Care Manager, 28(3), 240-245.

Hair, H. J. (2014). Power relations in supervision: Preferred practices according to social workers. Families in Society: The Journal of Contemporary Social Services, 95(2), 107-114.

Hawkins, P., \& Shohet, R. (2012). Supervision in the helping professions (4th ed.). Maidenhead, UK: Open University Press.

Henderson, P. (2009). A different wisdom: Reflections on supervision practice. London, UK: Karnac Books.

Hernández, P., \& McDowell, T. (2010). Intersectionality, power, and relational safety in context: Key concepts in clinical supervision. Training and Education in Professional Psychology, 4(1), 29-35. doi::10.1037/ a0017064

Hernández, P., \& Rankin IV, P. (2008). Relational safety and liberating training spaces: An application with a focus on sexual orientation issues. Journal of Marital and Family Therapy, 34(2), 251-264.

Hewson, D., \& Carroll, M. (2016). Reflective supervision toolkit. Hazelbrook, NSW: MoshPit.

Koenig, S. A. (2013). Courageous conversations. The Nebraska Lawyer (July/August), 16(4), 27-29. Retrieved from https://issuu.com/nebraskabar/docs/julyaug_2013

Ladany, N., Mori, Y., \& Mehr, K. E. (2013). Effective and ineffective supervision. The Counseling Psychologist, 41(1), 28-47.

Lamiani, G., Meyer, E. C., Leone, D., Vegni, E., Browning, D. M., Rider, E. A., ... Moja, E. (2011). Cross-cultural adaptation of an innovative approach to learning about difficult conversations in healthcare. Medical Teacher, 33(2), e57-e64. doi:10.3109/0142159X.2011.534207
Meyer, E. C., Sellers, D. E., Browning, D. M., McGuffie, K., Solomon, M. Z., \& Truog, R. D. (2009). Difficult conversations: Improving communication skills and relational abilities in health care. Pediatric Critical Care Medicine, 10(3), 352-359.

Nelson, M. L., Barnes, K. L., Evans, A. L., \& Triggiano, P. J. (2008). Working with conflict in clinical supervision: Wise supervisors' perspectives. Journal of Counseling Psychology, 52(1), 3-13.

Nelson, M. L., \& Friedlander, M. L. (2001). A close look at conflictual supervisory relationships: The trainee's perspective. Journal of Counseling Psychology, 48(4), 384-395.

Quarto, C. J. (2003). Supervisors' and supervisees' perceptions of control and conflict in counseling supervision. The Clinical Supervisor, 21(2), 21-37. doi:10.1300/J001v21n02_02

Rock, D. (2006). Quiet leadership: Six steps to transforming performance at work. New York, NY: HarperCollins.

Rousseau, D. M., Sitkin, S. B., Burt, R. S., \& Camerer, C. (1998). Not so different after all: A cross-discipline view of trust. Academy of Management Review, 23(3), 393-404.

Social Workers Registration Board. (2015). Supervision expectations for registered social workers: Policy statement. Retrieved from http://www.swrb.govt.nz/policy

Social Workers Registration Board (SWRB). (2018). SWRB Code of conduct 2018). Retrieved from https://swrb.govt. $\mathrm{nz} /$ for-the-public/code-of-conduct/

Tsui, M.-s., O’Donoghue, K., \& Ng, A. K. T. (2014). Culturally competent and diversity-sensitive clinical supervision. In C. E. Watkins \& Milne D. L (Eds.), The Wiley international handbook of clinical supervision (pp. 238-254). Chichester, NY: John Wiley \& Sons.

Veach, P. M., Yoon, E., Miranda, C., MacFarlane, I. M., Ergun, D., \& Tuicomepee, A. (2012). Clinical supervisor value conflicts: Low-frequency, but high-impact events. The Clinical Supervisor, 31(2), 203-227. doi:10.1080/07 325223.2013.730478

Werman, A., Adlparvar, F., Horowitz, J. K., \& Hasegawa, M. O. (2019). Difficult conversations in a school of social work: Exploring student and faculty perceptions. Journal of Social Work Education, 55(2), 251-264. doi:10.1080/104 37797.2018.1520665

Whyte, D. (2004). Five conversations on the frontiers of leadership. Leader to Leader, 33, 20-24. 